\title{
Egyptian Organo-Kaolinite / Chitosan Nano composite for Effective Removing Sulfate Ions from Groundwater
}

\section{Atef Mohamed Gad ${ }^{1}$, Mahmoud F. Mubarak ${ }^{2 *}$, Abd El Hay Ali Farrag $^{3}$, Aliaa Mokhtar Mohammed ${ }^{4}$}

${ }^{1,4}$ Assiut and new valley company for water and wastewater fax No: 088229347

${ }^{2}$ Petrolium Applications department, Egyptian Petroleum Research Institute (EPRI), Cairo, Egypt.

${ }^{3}$ Geology department, faculty of science, Assiut university, Assiut, Egypt.

*Corresponding author: Aliaa Mokhtar Mohammed, Assiut and new valley company for water and wastewater fax No: 088229347 E-Mail:aliaamokhtar230@yahoo.com

\section{Abstract}

In Upper Egypt, especially in the limestone carbonates scarp, groundwater is contains sulfate salts, which are considered more difficult to remove by conventional treatment plants for freshwater, used for drinking, domestic and industrial purposes. The study aims to prepare a reasonable adsorbent composite from Egyptian organo-kaolinite and prepared chitosan to remove the excess of sulfate ions from Assiut groundwater wells. Therefore, the modified organo-kaolinite was treated with prepared modified chitosan as a composite media filtration to treat groundwater. In this study, the prepared chitosan was characterized by using X-ray diffraction (XRD). FTIR and scanning electron microscopy (SEM) and its efficiency for removing sulfate have been tested through batch and experimental column studies.

The results revealed that the adsorption of sulfate ions is optimum at $\mathrm{pH}$ range $4-8$. The maximum sulfate ions adsorption capacities were found $2.88 \mathrm{mg} / \mathrm{g}$, after about $65 \mathrm{~min}$ contact time. The regeneration study illustrated that the prepared composite could be used up to 5 times with maximum sulfate ions percentage removal of $62.33 \%$, achieved after the 5th cycle. The Chitosan modified kaolin clay mineral showed 
higher adsorption capacity towards sulfate ions with other adsorbents as in the literature.

\section{Keywords: Groundwater, Sorted Sand, Organo kaolinite, Chitosan, Composite, Sulfate, Egyptian, Assiut.}

\section{Introduction}

Sulfate ions are present in groundwater in some Upper Egypt localities at significant concentrations, harmful to health and causing many pipelines to scale deposition problems. It is of great importance to remove them by traditional methods.

There are two primary sources for the occurrence of sulfate ions in groundwater. The first occurs in shallow, unconfined aquifers that receive large inputs of sulfate from atmospheric deposition, fertilizer use, and land application of animal wastes. These sources, however, should not result in concentrations exceeding the permissible limit $(250 \mathrm{mg} / \mathrm{L})$. The 2 nd one occurs in Aquifers' underlying soils rich in gypsum with high concentrations of sulfate, often above the allowable limit. Usually, the appearance of sulfate ions in groundwater wells when the location of those wells are contacting the carbonate rocks that contain a high ratio of gypsum rocks and anhydrite, and according to the water is a strong solvent, it dissolves those elements that make up the adjacent rocks, making groundwater riched in those elements including That's sulfates [1].

Due to the adverse effects of sulfates on the taste, color, and odor of the water used for drinking purposes, as well as its harmful effect on general health, as high concentrations of sulfates in drinking water cause diarrhea [2], it is necessary to search an effective method to remove sulfate ions from the drinking water.

The conventional oxidation followed by filtration plants is the most common treatment technique used to purify Egypt's groundwater. Still, this method effectively removes iron, manganese, and turbidity, but it cannot remove sulfate or chlorides. Therefore, the organo-kaolinite/ Chitosan Composite is considered one of the ion exchange methods for removing sulfate or chlorides, which are negative charge ions, so this method is considered one of 
the most promising methods for eliminating the excess of sulfate ions from the groundwater. Wetlands [1][3].Chitosan is highly abundant and non-toxic; it is considered highly hydrophilic, contained many hydroxyls, and amino groups, thereby presenting good compatibility with clay minerals[4].

So, this work intended to prepare a composite of kaolinite that abundance in several areas in Egypt, and it treated with a surface-active agent that will activate the interlayer's of kaolinite before treated it with chitosan to obtained a convincing composite to remove sulfate from groundwater as it increases the Positive charge of the prepared composite.

\section{Experimental Study}

\subsection{Materials}

- Groundwater samples: were taken from about 75 groundwater wells producing drinking water covering all Assiut District places to identify the most contaminated wells by sulfates.

- Natural kaolinite: obtained from Abu Zenima area, Sinai Region, Egypt, this natural kaolinite was grinding with grain size less than $0.8 \mathrm{~mm}$ by using an agate mortar and mechanical sieves for the preparation of oregano kaolinite/Chitosan composite.

-Shrimp shells: were collected from a local source of Alex. City, Egypt, as a source of chitin for prepared chitosan.

- Sorted sandstone: A grain size of $0.7 \mathrm{~mm}$ to $1.25 \mathrm{~mm}$ was used as a filter in a packed column.

- Chemicals: Sodium hydroxide pellets, hydrochloric acid (30\%), and Anhydrous glacial acetic acid (100\%) to the purification of chitosan.

\subsection{Procedure}

\subsubsection{Preparation of kaolinite}

Kaolin sample from Abu -zenima area, Sinai Region, was oven-dried at $80{ }^{\circ} \mathrm{C}$ for $24 \mathrm{~h}$. The dried kaolin was then pulverized by using a mortar and sieved through a 325-mesh sieve. The purification method was conducted through sedimentation regarding a previous study[1]. Purified kaolin was then redried at $90^{\circ} \mathrm{C}$ overnight $[1]$. 


\subsubsection{Modification of kaolinite}

\section{i. Purification and activation of kaolinite}

The raw kaolin mixed with distilled water and the produced suspension were sieved by passed through a 320 mesh screen $(\leq 50$ $\mu)$ to separate larger particles. It must be filtered the underflow and dried the cake in the oven at $90^{\circ} \mathrm{C}$ overnight; after that, the dried cake was then ground with a mortar and pestle. The purified kaolinite was treated with $2 \mathrm{M}$ hydrochloric acid at room temperature of $25^{\circ} \mathrm{C}$ for 48 hours at $150 \mathrm{rpm}$ using a mechanical shaker to remove the free quartz. The higher content of quartz may decrease the performance of the composites. The clay was separated by centrifugation and washed several times to remove the excess acid. The acid-activated kaolinite was dried in the oven at $90^{\circ} \mathrm{C}$ overnight [1][5].

\section{ii. Extract of chitosan from shrimp shells}

The extraction of chitosan from shrimp shells was performed as per the procedure earlier reported [6].Firstly it must be washing the raw shrimp shells with water, and drying it under vacuuming air, after that grind it in a mortar with a pestle, after that must be soaking the obtained powder of the shrimp shells in $1 \mathrm{M} \mathrm{NaOH}$ for two days, then washed, and dried it, after that must be demineralized by using Hydrochloric acid $1 \mathrm{M}$, using sodium hydroxide $1 \mathrm{M}$ to deproteinizing, using $\mathrm{KMnO} 4$ to discolored, and using the oxalic acid to get chitin powder

The chitin was then subjected to deacetylation using 50\% $\mathrm{NaOH}$, which was repeated to get a higher degree of deacetylation in chitosan[7].

\section{iii. Preparation of Kaolinite / Chitosan Composite.}

The chitosan dissolved in $100 \mathrm{~mL}$ of acetic acid and the kaolinite was added to this chitosan solution, followed by mixing the component and agitated it by a sonicator for a half-hour. the mixture can be sprayed by drop wise solution of $15 \% \mathrm{NaOH}$ and $90 \%$ ethanol in a volume ratio of 4:1to neutralization. Must be washed the produced composite beads several times, and after that 
must be dried in an oven at $70^{\circ} \mathrm{C}$ overnight. After drying the bead, it was ground to reduce its particle size[7].

\subsubsection{Characterization of the raw materials and composites}

The composite adsorbents prepared were characterized using different characterization techniques. The prepared composites' morphology and elemental composition were analyzed using a Scanning electron microscope equipped with an Oxford EDX spectrometer.

$\mathrm{X}$-ray diffraction (XRD) patterns were recorded from 2.0 to $70^{\circ} 2 \theta$ on a Siemens D-5000 diffractometer at $0.02^{\circ} \mathrm{S}^{-1}$. The Fourier transformed infrared spectroscopy spectra of the composites were recorded using a Shimadzu FT-IR 8400S machine.

\subsubsection{Batch adsorption study}

A series of batch scale adsorption experiments for evaluating the affinity of adsorbents (Organokaolinite / chitosan composite) for sulfate ions sorption was performed in duplicate sets in $250 \mathrm{~mL}$ conical flasks having $100 \mathrm{~mL}$ of sulfate solution.

A batch adsorption study was performed to measure the effectiveness of sulfate ions adsorption for organo-kaolinite/ chitosan composite. These experiments were carried out by utilizing $250 \mathrm{~mL}$ conical flasks and an orbital shaking incubator at a specific controlled temperature (at room temperature) and 220 rpm. Samples were drawn every $10 \mathrm{~min}$, and it was left to precipitate for another $10 \mathrm{~min}$ and filtered through a nitrocellulose filter $(0.45 \mu \mathrm{m})$. The filtrates were analyzed using a spectrophotometer (HACH DR 6000). Batch adsorption data were analyzed using Eq. (1) to obtain the adsorption capacity and the removal effectiveness of prepared composite for sulfate ions from raw groundwater.

$\%$ Removal efficiency $=\frac{\text { Influent(mg } / 1)-E \text { Effluent(mg } / 1)}{\text { Influent }(m g / 1)} \quad i=\frac{C_{0}-C_{e}}{C_{0}} \quad$ Eq. (1)

Where (i) is removal efficiency and $\left(\mathrm{C}_{\mathrm{o}}\right)$ and $\left(\mathrm{C}_{\mathrm{e}}\right)$ are the initial and final concentrations $(\mathrm{mg} / \mathrm{l})$ of the $\mathrm{SO}_{4}^{-2}$ ions solutions, respectively. 
This Batch study examined the essential three factors on the success of the prepared organo-kaolinite /chitosan composite the removal of sulfate ions from the contaminated groundwater, namely the effect of $\mathrm{pH}$ and the ideal contact time and the appropriate dose of the adsorbent to determine the ideal conditions to achieve the best results for adsorption of sulfate ions by prepared organo-kaolinite /chitosan composite.

\section{Result and Discussion}

Many parameters may affect the kaolin/polymer interactions, such as the shape and size of kaolin particles, the charge on its surface, the concentration of kaolinite and polymer, the polymers molecular weight, the polymers hydrolyzing groups, $\mathrm{pH}$, temperature, etc.[8]. So, the interaction between chitosan and kaolinite was not stable in acidic media. Simultaneously, the formation of the composite appeared when the starting use of the addition Drops of the suspension in alkaline media, and what helped retain the spherical shape of the beads is the rapid neutralization of acetic acid [8]. The beads were stable, and kaolinite lost its identity due to bead formation. We further centrifuged the mixture containing the beads. This time kaolinite couldn't separate itself from the beads. Therefore, this study confirmed the $\mathrm{pH}$ is dependent on the nature of the composite fabrication process.

\subsection{XRF \& XRD Interpretation}

XRF analysis shown that raw kaolin was rich in $\mathrm{SiO}_{2}(49.0 \%)$ and $\mathrm{Al}_{2} \mathrm{O}_{3}(\sim 33.0 \%)$ and contained small amounts of metal oxides of $\mathrm{Ca}, \mathrm{Mg}, \mathrm{Na}, \mathrm{Fe}, \mathrm{K}$ and $\mathrm{Ti}$, and the loss on ignition (LOI) was $10.85 \%$ as shown in (Table 1 ).

Table (1). The chemical analysis of Egyptian Kaolinite by XRF.

\begin{tabular}{|l|c|c|c|c|c|c|c|c|c|c|}
\hline Composition & $\mathrm{SiO}_{2}$ & $\mathrm{AI}_{2} \mathrm{O}_{3}$ & $\mathrm{Fe}_{2} \mathrm{O}_{3}$ & $\mathrm{MnO}$ & $\mathrm{TiO}_{2}$ & $\mathrm{CaO}$ & $\mathrm{MgO}$ & $\mathrm{Na}_{2} \mathrm{O}$ & $\mathrm{K}_{2} \mathrm{O}$ & L.O.I \\
\hline Content (wt \%) & 49.4 & 31.8 & 3.52 & 0.31 & 1.25 & 0.61 & 0.29 & 0.33 & 0.64 & 11.85 \\
\hline
\end{tabular}

The XRD pattern of Raw Egyptian kaolin is shown in Fig.

1(a). The kaolin samples showed diffraction patterns where the 
peak position of diffraction intensity at $2 \theta$ is $12.42 ; 18.91 ; 21.38$; 24.09; and 26.72 [9]. The XRD pattern of prepared chitosan identifying its crystallinity was represented in Fig. 1(b). Two characteristic broad diffraction peaks at $2 \theta$, around 10.42 and 19.92, were related to crystal-1 and crystal-2, respectively, in the chitosan structure[9]. While Figure 1(c) shows the appearance of many peaks along the 2 theta axis than the previous Figures 1(a), and 1(b), The appearance of these peaks is due to the increased presence of amino groups and hydroxyl groups in the prepared composite, and this is indicated that the success of the organokaolin/chitosan composite preparation process.

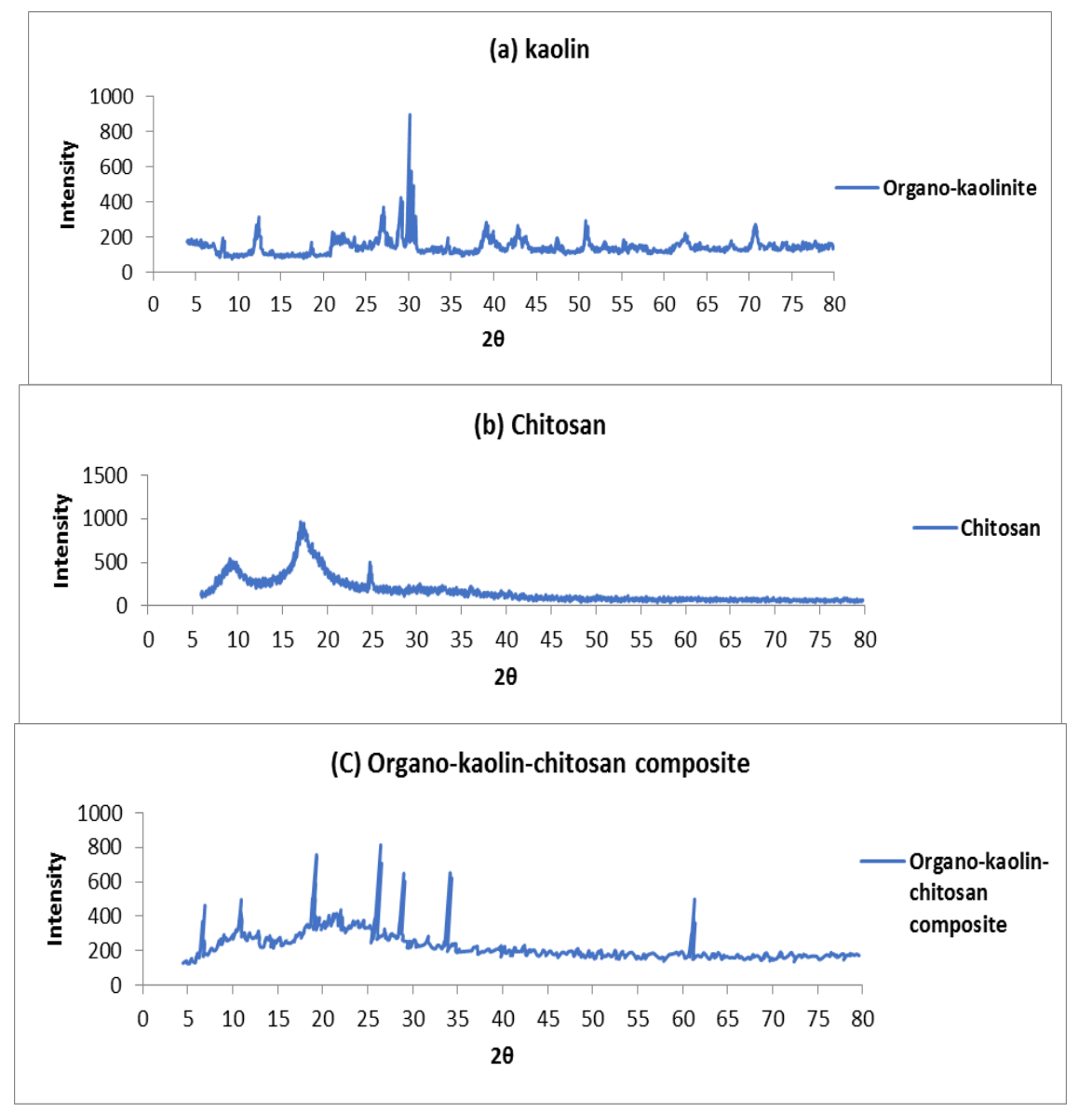

Figure (1) XRD diffraction of kaolinite (a), Chitosan (b), and oregano-kaolin-Chitosan Composite (c). 
3.2. Scanning electron microscopic analysis (SEM) of the kaolinite / Chitosan Composite

The SEM image illustrated the variation in the raw kaolinite and the prepared composite's morphological features, so in the case of raw kaolinite, the hexagonal crystals appear with rough surfaces and irregular edges as shown in Figure 2(a)[10]. Still, the prepared composite's crystals became homogeneous, and the surfaces became smooth, and the edges became regular and rounded, as shown in Figure 2(b)[10]. These uniform grain formation features are highly desirable for many applications. The uniform and rounded - shape and smooth surface of the composite will certainly exhibit better properties than kaolin or chitosan if applied separately.

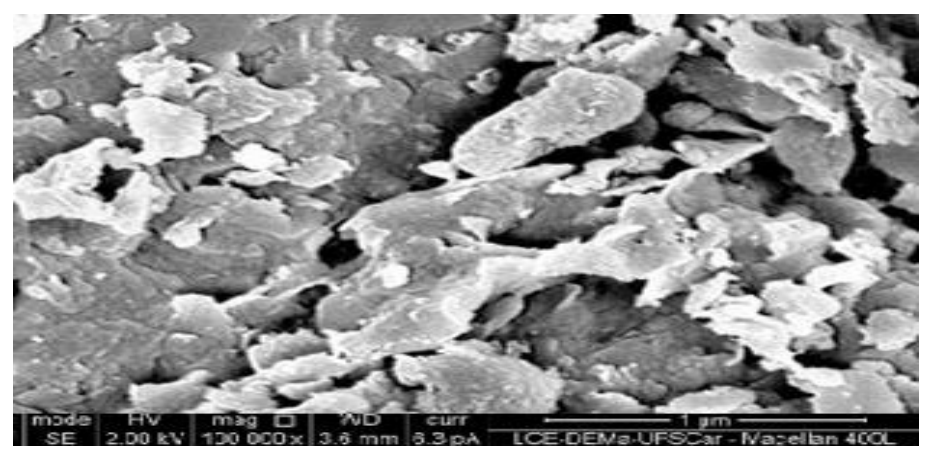

a. Raw Kaolinite

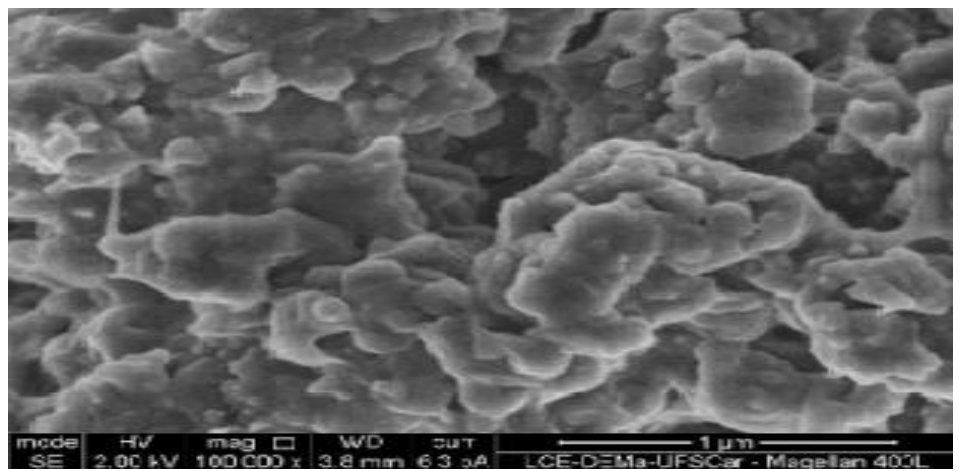

b. Organo-Kaolin-ChitosanComposite

Figure (2) scanning electron microscopic analysis (SEM) of the kaolinite (a) and organo-kaolin /Chitosan Composite (b). 
Fourier transforms infrared spectroscopy (FT-IR)Interpretation

Figure (3) shows the significant difference between the raw kaolin before Figure 3(a) and after treated it with chitosan Figure 3(b). It was characterized the prepared composite from raw kaolin by the appearance of plenty peaks for the absorption bands around $3750 \mathrm{~cm}^{-1}$, which are due to the stretching vibration of $\mathrm{O}-\mathrm{H}$ groups that overlapped to the stretching vibration of the N-H band [11]. At $1000 \mathrm{~cm}^{-1}$, the peak became wider and shifted from $1032.65 \mathrm{~cm}^{-1}$ to $996.64 \mathrm{~cm}^{-1}$. The absorption peak in this area is characteristic of $\mathrm{Si}-\mathrm{O}$ absorption of kaolinite materials, and the appearance of widening and shifting for absorption bands was also detected at area $400-500 \mathrm{~cm}^{-1}[12]$. Figure (3) the absorption taking place at this range comes from the stretch vibration of Si-O. This change implies that the modification with the surfactant has altered the silicate environment of the kaolin [6][13].

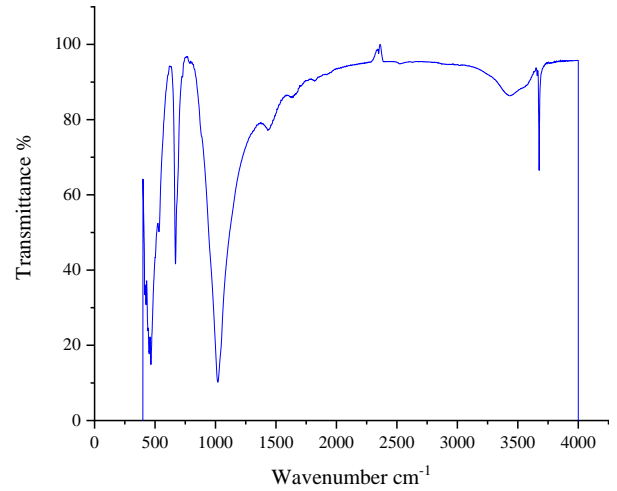

a. Raw Kaolinite

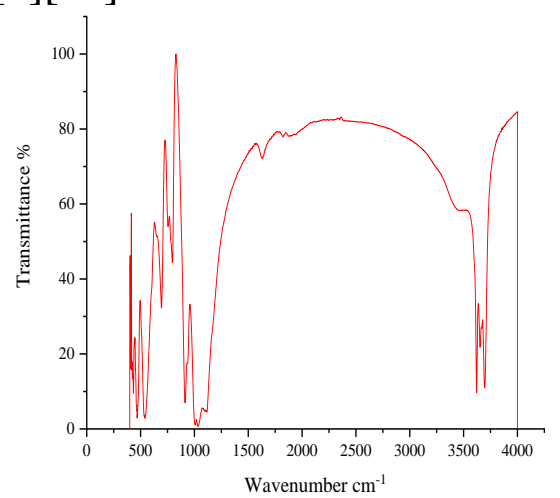

b. Organo-Kaolin-Chitosan Composite

Figure (3) FTIR spectrum of raw kaolinite(a) and after its composite with chitosan(b).

\subsection{Study of sulfate ions adsorption in raw groundwater}

Isotherm adsorption is an approach commonly used to determine adsorption capacity. Besides, this approach is often used to draw a relationship between the adsorbent's weight and the amount of sulfate being adsorbed in an equilibrium state. In this study, the Langmuir equation on isotherm adsorption was used regarding previous studies suggesting that adsorption of organic 
molecules onto the kaolin surface fits Langmuir's theory [14][15][16].Varying sulfate concentrations conducted the adsorption process. In this study, the concentration was varied into $100,150,200,250,300,350,400,450,500,550,600$, and 840 $\mathrm{mg} / \mathrm{L}$. The condition was set at $\mathrm{pH}$ ranged (from 7 to 7.8 ) while the time of contact between the adsorbent and sulfate ions was set for three hours[17]. The pattern of sulfate ions adsorption by modified kaolin/chitosan composite as approached by Langmuir's theory. Table (2) leads to a deduction that the adsorption process of the adsorbents tended to suit the Langmuir theory of isotherm adsorption. Table 2 showed that R2 > 0.9 for all adsorbents, making it possible to determine the adsorption capacity for each adsorbent by using the Langmuir model of isotherm adsorption.

Table (2) Langmuir and Freundlich parameters of organokaolinite/ chitosan composite for the adsorption of sulfate ions

\begin{tabular}{|l|l|l|l|l|l|}
\hline \multicolumn{2}{|l|}{ Langmuir } & \multicolumn{3}{l|}{ Freundlich } \\
\hline qm & $K_{\text {L }}$ & R2 & n & K$_{\text {F }}$ & R $_{2}$ \\
\hline 526.316 & 0.002604 & 0.98 & 2.5 & 28.9734 & 0.968798 \\
\hline
\end{tabular}
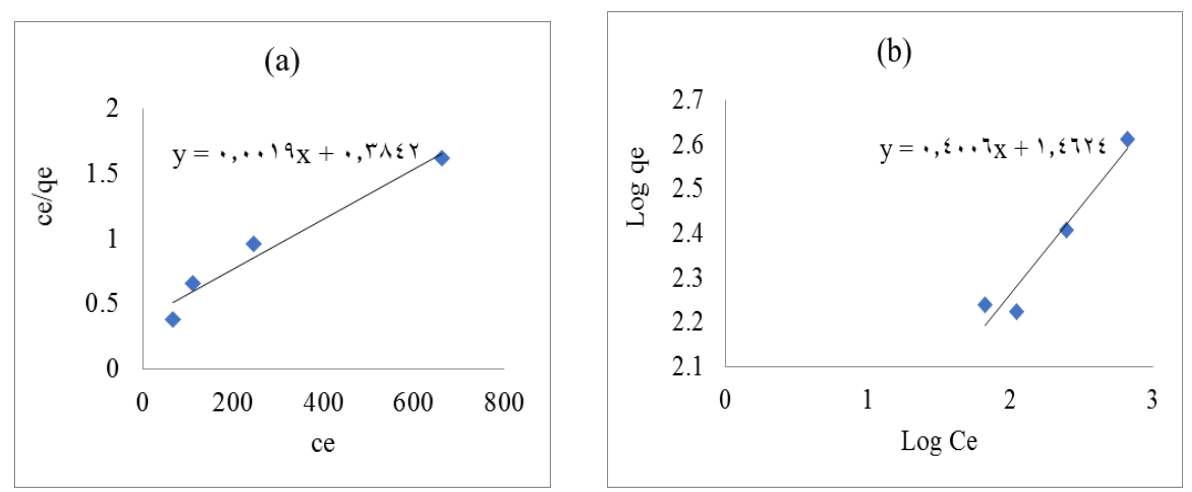

Figure (4) Isotherms models (a) Langmuir adsorption (b) Freundlich adsorption. 


\subsubsection{Effect of Contact Time on sulfate ions Removal}

The effect of contact time is presented in Figure (5) which showed that the longer of mixing time the higher the displacement of sulfate ions. For about the first 20 minutes, the sulfate ions adsorbed was the same. From the $8-10 \mathrm{~min}$, the concentration of sulfate ions adsorbed decreased. This is due to not achieving equilibrium between the number of sulfate ions adsorbed by organo- kaolinite/ chitosan composite and the number of sulfate ions remaining in the groundwater, which leads to the active side adsorbent organo- kaolinite/ chitosan composite not fully binding the sulfate ions. At 100 minutes in a stirring, optimum contact time of sulfate ions adsorption occurs. It showed that amount of sulfate ions adsorbed by Chitosan composite and remained in the solution were in equilibrium. Chitosan composite as adsorbent has bonded sulfate ions from groundwater to its surface-active side. At contact time between chitosan composite and sulfate ions for 15 minutes could remove sulfate ions by concentration $10 \mathrm{mg} \mathrm{L}-1$ until $81.68 \%$ or $8.168 \mathrm{mg} \mathrm{L-1}$. After 15 minutes to 20 minutes, the ability of the composite to adsorb sulfate ions decreased. The amount of sulfate ions adsorbed been reduced because the binding of functional groups on the surface of adsorbent and sulfate ions was weaker, so sulfate ions were left in the solution. As longer the contact time between the sulfate ions and the adsorbent composite, the ions were more adhere to the adsorbent, and the adsorption efficiency was higher. [18].

Contact time of sulfate ions adsorption from groundwater was studied from the determination of absorbance after adsorbed using organo- kaolinite/chitosan composite at groundwater $\mathrm{pH}$ before treatment, i.e., 5. The effect of contact time was shown in Figure (5). 


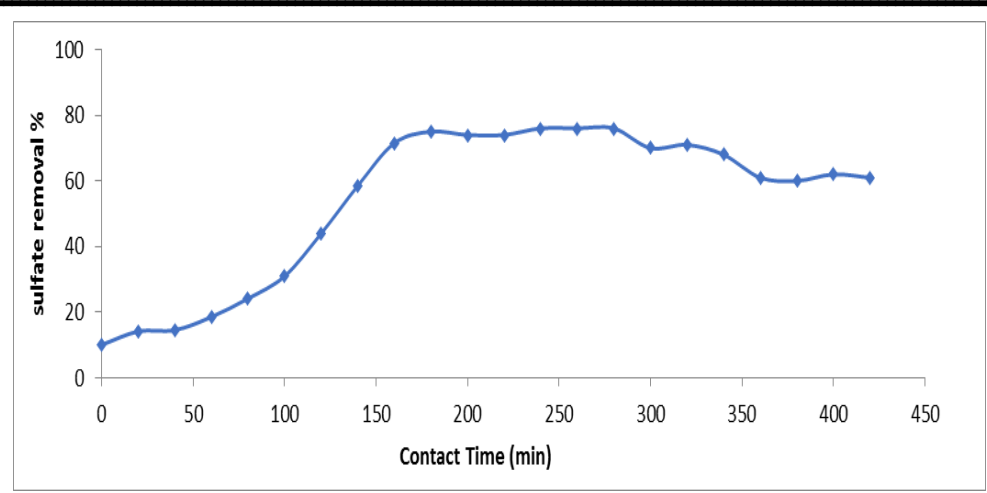

Figure (5) Effect of contact Time on the adsorption of sulfate ions by organo- kaolinite/chitosan composite.

\subsubsection{Influence of $\mathbf{p H}$ on Sulfate ions Adsorption}

The absorption of sulfate ions by the prepared composite is greatly influenced by the water's $\mathrm{pH}$ degree. An extensive range of $\mathrm{pH}$ values conducted an examination study to determine the best suitable $\mathrm{pH}$ conditions to achieve the prepared compound's best adsorption of sulfate ions. This study was conducted by using water with different concentrations of $\mathrm{pH}$ values were ranged from ( 2 to 12) using an amount of the adsorbent composite weighing about $50 \mathrm{~g}$, and this study resulted in the best adsorption of sulfate ions in the groundwater at the level of neutral $\mathrm{pH}$ as shown in Figure (6).

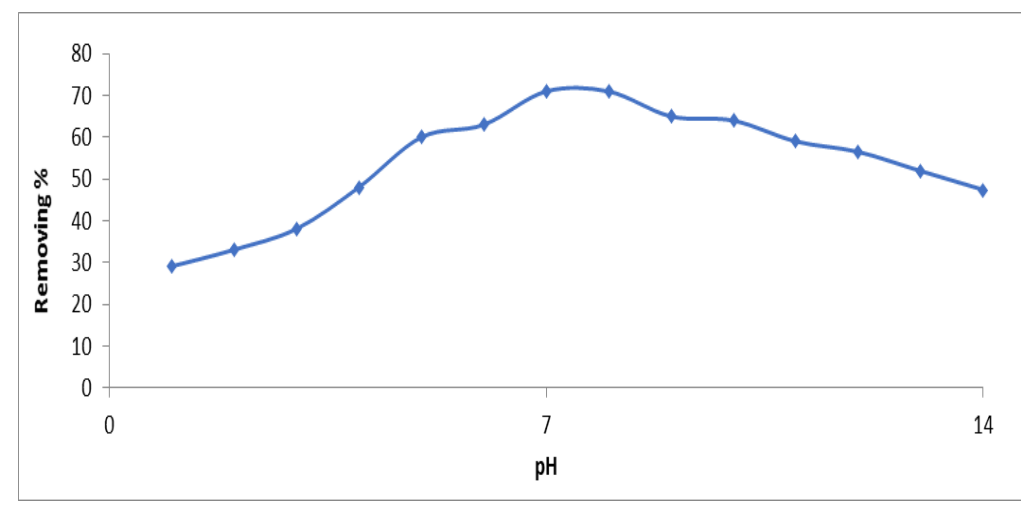

Figure (6) Influence of $\mathrm{pH}$ on the adsorption of sulfate ions by organo- kaolinite/chitosan composite. 


\subsubsection{Effect of Adsorbent Dose}

Determine the optimum dosage of kaolinite/chitosan composite for removing sulfate was done by changing their dosage from 0.5 to $2.5 \mathrm{~g} / \mathrm{L}$ keeping other parameters constant in Figure (7). A measured quantity of kaolinite was taken in $100 \mathrm{~mL}$ sulfate ions solution at fixed $\mathrm{pH} 7.5$ and sulfate ions concentration until equilibrium. Effective dose was chosen based on sulfate ions removal (\%) at different doses of kaolinite/ chitosan composite. Impact of solution $\mathrm{pH}$ on sulfate ions adsorption and removal was evaluated at neutral $\mathrm{pH}(7-8)$ by keeping another factor such as the initial concentration of sulfates $(441 \mathrm{mg} / \mathrm{L})$, kaolinite/chitosan composite dosage $1 \mathrm{~g} / \mathrm{L}$, and room temperature constant. Samples were agitated on a rotary shaker and were collected at equilibrium.

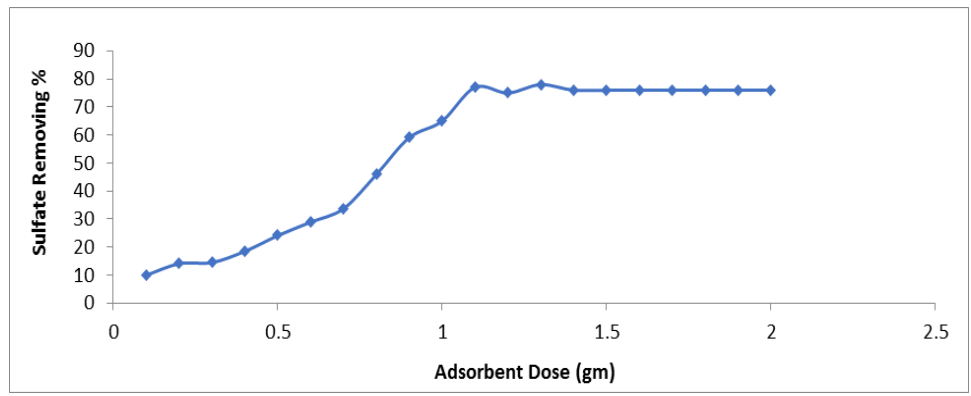

Figure (7) Effect of Adsorbent dose on the adsorption of sulfate ions by organo- kaolinite/chitosan composite.

\subsubsection{Effect of Initial Concentration}

The effect of initial concentration on adsorption capacity and ions removal $(\%)$ by organo-kaolinite/ chitosan composite was sulfate determined at different initial concentrations of sulfate ions $(160$ to $850 \mathrm{mg} / \mathrm{L})$ at constant $\mathrm{pH} 7.6$, prepared composite $(1 \mathrm{~g} / \mathrm{L})$ at room temperature. Groundwater samples were taken after 20, $30,60,80,100,120$, and $180 \mathrm{~min}$ until equilibrium was reached in the solution. Groundwater samples were shaken at $150 \mathrm{rpm}$ with a mechanical shaker and centrifuged for $10 \mathrm{~min}$ at $3000 \mathrm{rpm}$ [20]. The samples were filtered with a Whatman filter paper $(0.45 \mu \mathrm{m})$. The residual of sulfate ions concentration was measured in the filtrate with Spectrophotometer (DR 6000, HACH, Germany). The 
sulfate measurement's liability was ensured by running standard solutions of sulfate ions after every 15 samples. The calibration curve obtained with standard solutions of sulfate using AAS had $\mathrm{R} 2=0.9668$.

\subsection{Column adsorption study}

According to [1], fixed-bed column adsorption experiments were conducted in a cylindrical column with an internal diameter of $2.5 \mathrm{~cm}$ and a height of $30 \mathrm{~cm}$. and it was filled with an adsorbent bed (composed of 1: 5 chitosan and sorted sandstone respectively) with different heights 4,6 , and $8 \mathrm{~cm}$, as specified for each experiment. In every experiment, a sulfate ion-containing raw groundwater of a particular initial concentration (160-841 mg / L) was flowed to the top of the column under gravity action at a fixed flow rate $(2.5-10 \mathrm{ml} / \mathrm{min})$.All laboratory experiments were conducted at room temperature and had a neutral $\mathrm{pH}$ of 7-7.8 [18]. Samples for determining the concentration of metal ions were collected at regular time intervals at the column base. Continuous adsorption experiments were stopped only after the column was thoroughly exhausted. After was plotting the breakthrough curves $\left(\mathrm{C}_{\mathrm{t}} / \mathrm{C}_{0}\right.$ vs. time $)$, the $50 \%$ breakthrough capacity Figure (8).

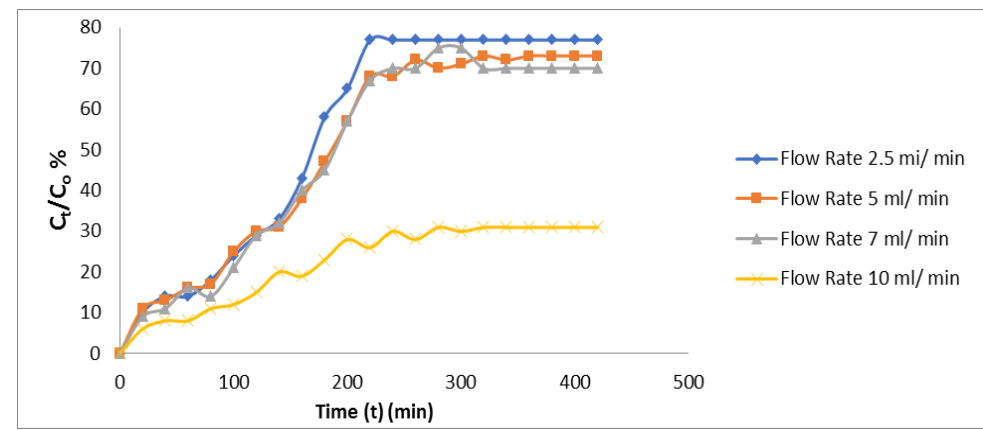

Figure (8) Effect of the flow rate on the maximum ability of adsorption.

\subsection{Desorption and Regeneration Analysis}

Regeneration studies are required to perform as it will much decrease the product cost. The regeneration study provides an idea about adsorbent's reusability, which increased the adsorption phenomenon's potency. Many works of literature did not discuss regeneration and the mechanism involved in this process. 
Literature explained that regeneration could be achieved, and sorbent extraction can be obtained using some common solvents like hydrochloric acid, nitric acid, sodium chloride, sodium hydroxide, etc.[20]. Based on the adsorption equilibria and kinetic studies, assumptions have been made. Hence exact mechanism involved during the process is not well defined in existing studies[21].

Desorption of the adsorbed anions (sulfate salts) from the organo - kaolinite/chitosan composite was also studied in a batch experimental system. Various factors are probably involved in determining efficiencies of sulfate ions desorption, such as the extent of hydration of the metal ions and sorbent microstructure. Figure (9) illustrates sulfate ion compounds desorption with $\mathrm{NaOH}, \mathrm{NaHCO} 3, \mathrm{HCl}$, and $\mathrm{NaCl}$. According to the results, $0.1 \mathrm{M}$ $\mathrm{NaOH}$ showed the best desorption efficiency among all the solvents. In an alkaline solution, the surface charge of organokaolinite/chitosan composite possibly changed, thereby causing detachment of the sulfate ions from the adsorbent. To show the reusability of the organo- kaolinite/chitosan composite, the adsorption-desorption cycle was repeated 6 times by using the same organo -kaolinite/chitosan- composite. As shown in Figure (9), the removal efficiency remained as $90.98 \%$ after six cycles. The result indicated that the prepared organo-kaolinite / chitosan composite could be effectively used for groundwater treatment containing sulfate ions salts at least for 6 times.

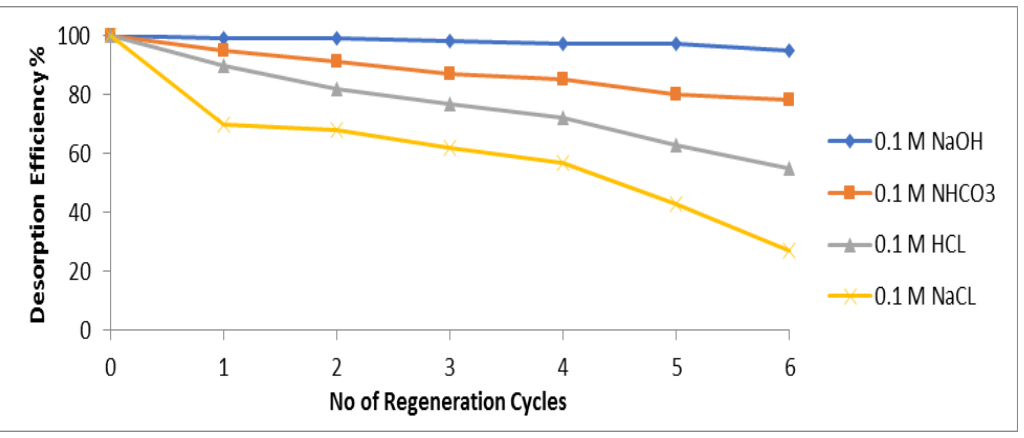

Figure (9) Removal efficiency of sulfate by prepared composite. 


\section{Conclusion}

This study proposed adsorption as a robust technique for sulfate ions removal from groundwater. The adsorption process requires a robust media of known kinetics and equilibrium capacity. Consequently, this study explored the use of chitosankaolinite composite. The media was synthesized, characterized, and test in sulfate removal from raw groundwater. Results revealed that the magnitude of adsorption was primarily dependent on the solution's initial $\mathrm{pH}$ and the sorbent dosage. In particular, the performance was favored at $\mathrm{pH} 2$. This is consistent because amine groups from the chitosan are protonated at shallow $\mathrm{pH}$ values.

Meanwhile, a maximum media dosage in the range of $0.3-0.5$ $\mathrm{g}$ of the chitosan-kaolinite composite was found to be required for approximately $150 \mathrm{mg} / \mathrm{g}$ adsorption. Though these results are only preliminary in an exhaustive study still to be conducted, they indicate that chitosan-kaolinite composite is a potential material for sulfate removal. There is a need to conduct more adsorption kinetics, equilibrium, and fixed-bed dynamic studies to generate enough adsorbed design data.

\section{References}

[1] A. E. H. A. Farrag, T. Abdel Moghny, A. M. G. Mohamed, S. S. Saleem, and M. Fathy,(2017) : "Abu Zenima synthetic zeolite for removing iron and manganese from Assiut governorate groundwater, Egypt," Appl. Water Sci., vol. 7, no. 6, pp. 3087-3094, 2017, doi: 10.1007/s13201-016-0435-y.

[2] L. C. Backer, E. Esteban, C. H. Rubin, S. Kieszak, and M. A. McGeehin,(2001): "Assessing acute diarrhea from sulfate in drinking water," J. / Am. Water Work. Assoc., vol. 93, no. 9, pp. 76-84, 2001, doi: 10.1002/j.1551-8833.2001.tb09288.x.

[3] M. Elsheikh, H. Guirguis, and A. Fathy,(2018) :"Removal of iron and manganese from groundwater: A study of using potassium permanganate and sedimentation," MATEC Web Conf., vol. 162, pp. 1-7, 2018, doi: 10.1051/matecconf/201816205018.

[4] W. S. Wan Ngah, L. C. Teong, and M. A. K. M. 
Hanafiah,(2011): "Adsorption of dyes and heavy metal ions by chitosan composites: A review," Carbohydr. Polym., vol. 83, no. 4, pp. 1446-1456, 2011, doi: 10.1016/j.carbpol.2010.11.004.

[5] S. C. Dey, M. Al-Amin, T. U. Rashid, M. Ashaduzzaman, and S. Md Shamsuddin,(2016): " $\mathrm{pH}$ Induced Fabrication of Kaolinite-Chitosan Biocomposite," Int. Lett. Chem. Phys. Astron., vol. 68, no. July, pp. 1-9, 2016, doi: 10.18052/www.scipress.com/ilcpa.68.1.

[6] H. El Fargani, R. Lakhmiri, H. El Farissi, and A. Albourine,(2017): "Removal of anionic dyes by silicachitosan composite in single and binary systems : Valorization of shrimp co- product ' Crangon - Crangon' and ' Pandalus Borealis ," no. January, 2017.

[7] E. S. de Alvarenga,(2011): "Characterization and Properties of Chitosan," Biotechnol. Biopolym., no. May, 2011, doi: $10.5772 / 17020$.

[8] H. Yan et al.,(2014): "Mechanochemical modification of kaolin surfaces for immobilization and delivery of pesticides in alginate-chitosan composite beads," Polym. Bull., vol. 71, no. 11, pp. 2923-2944, 2014, doi: 10.1007/s00289-014-1231-1.

[9] M. Shaban, M. E. M. Hassouna, F. M. Nasief, and M. R. AbuKhadra, (2017): “Adsorption properties of kaolinite-based nanocomposites for $\mathrm{Fe}$ and $\mathrm{Mn}$ pollutants from aqueous solutions and raw ground water: kinetics and equilibrium studies," Environ. Sci. Pollut. Res., vol. 24, no. 29, pp. 22954 22966, 2017, doi: 10.1007/s11356-017-9942-0.

[10]A. Maged, I. S. Ismael, S. Kharbish, B. Sarkar, S. Peräniemi, and A. Bhatnagar, (2020):"Enhanced interlayer trapping of $\mathrm{Pb}$ (II) ions within kaolinite layers: intercalation, characterization, and sorption studies," Environ. Sci. Pollut. Res., vol. 27, no. 2, pp. 1870-1887, 2020, doi: 10.1007/s11356-019-06845-w.

[11]V. T. Le et al.,(2018): "A Novel Cross-Linked Magnetic Hydroxyapatite/Chitosan Composite: Preparation, Characterization, and Application for Ni(II) Ion Removal from Aqueous Solution," Water. Air. Soil Pollut., vol. 229, no. 3, 
2018, doi: 10.1007/s11270-018-3762-9.

[12]B. J. Saikia and G. Parthasarathy,(2010): "Fourier Transform Infrared Spectroscopic Characterization of Kaolinite from Assam and Meghalaya, Northeastern India," $J$. Mod. Phys., vol. 01, no. 04, pp. 206-210, 2010, doi: 10.4236/jmp.2010.14031.

[13]Q. A. Bhatti, M. K. Baloch, S. Schwarz, and G. Petzold,(2012): "Impact of Various Parameters Over the Adsorption of Polyvinylpyrrolidone onto Kaolin," J. Dispers. Sci. Technol., vol. 33, no. 12, pp. 1739-1745, 2012, doi: 10.1080/01932691.2011.629530.

[14]M. Khairy, H. A. Ayoub, F. A. Rashwan, and H. F. AbdelHafez,(2018): "Chemical modification of commercial kaolin for mitigation of organic pollutants in environment via adsorption and generation of inorganic pesticides," Appl. Clay Sci., vol. 153, no. December, pp. 124-133, 2018, doi: 10.1016/j.clay.2017.12.014.

[15]M. J. Ahmed, B. H. Hameed, and E. H. Hummadi,(2020): "Review on recent progress in chitosan/chitin-carbonaceous material composites for the adsorption of water pollutants," Carbohydr. Polym., vol. 247, no. February, p. 116690, 2020, doi: 10.1016/j.carbpol.2020.116690.

[16]Z. Yi, J. Yao, M. Zhu, H. Chen, F. Wang, and X. Liu,(2016): "Kinetics, equilibrium, and thermodynamics investigation on the adsorption of lead(II) by coal-based activated carbon," Springerplus, vol. 5, no. 1, 2016, doi: 10.1186/s40064-016-2839-4.

[17]R. Hosny, M. Fathy, M. Ramzi, T. Abdel Moghny, S. E. M. Desouky, and S. A. Shama,(2016): "Treatment of the oily produced water (OPW) using coagulant mixtures," Egypt. J. Pet., vol. 25, no. 3, pp. 391-396, 2016, doi: 10.1016/j.ejpe.2015.09.006.

[18]R. Article,(2018): "SF Journal of Nanochemistry and Nanotechnology Chitosan / Bentonite Nanocomposites for Wastewater Treatment: A Review," 2018.

[19]A. Kausar et al., (2019):"Preparation and characterization of chitosan/clay composite for direct Rose FRN dye removal 
from aqueous media: Comparison of linear and non-linear regression methods," J. Mater. Res. Technol., vol. 8, no. 1, pp. 1161-1174, 2019, doi: 10.1016/j.jmrt.2018.07.020.

[20]G. Z. Kyzas and D. N. Bikiaris,(2015): "Recent Modifications of Chitosan for Adsorption Applications :," pp. 312-337, 2015, doi: 10.3390/md13010312.

[21]R. Mudzielwana, M. W. Gitari, and P. Ndungu,(2019): "Performance evaluation of surfactant modified kaolin clay in $\mathrm{As}(\mathrm{III})$ and $\mathrm{As}(\mathrm{V})$ adsorption from groundwater: adsorption kinetics, isotherms and thermodynamics," Heliyon, vol. 5, no. 11, p. e02756, 2019, doi: 10.1016/j.heliyon.2019.e02756.

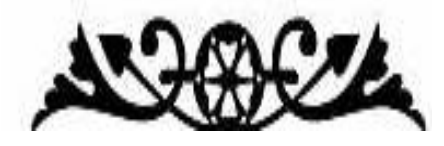




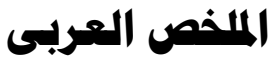

\section{متراكب عضوي باستخدام امتزاز ايونات الكبريتات هن المياه الجوفية}

$$
\text { نانوهتري للكاولينيت / شيتوزان في هركز أسيوط - هصر }
$$

عاطف مهمد جاد'، همهود فتحي هبارك²عبد الحي على فراج 3، علياء هختار

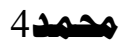

إدارة تطوير وبهوث المياه - شركة مياه الشرب والصرف الصهى بأسيوطوالوادى

$$
\text { البهب4 }
$$

$$
\text { المركز القومي المسرى لبهوث البترول البهول }
$$



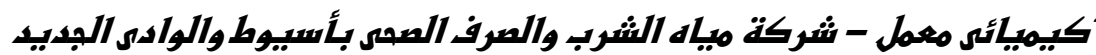

توجد أيونات الكبريتات في المياه الجوفية في صعيد مصر بتركيزات كبيرة

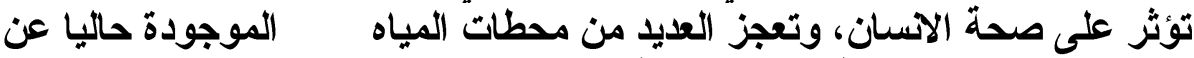

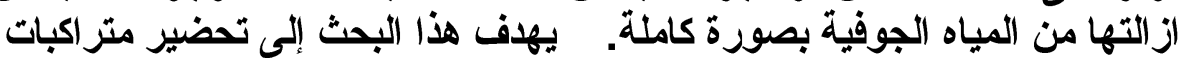



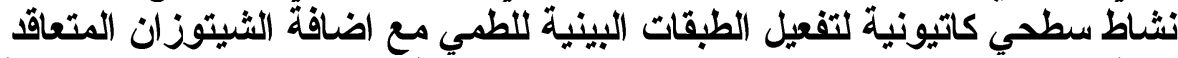

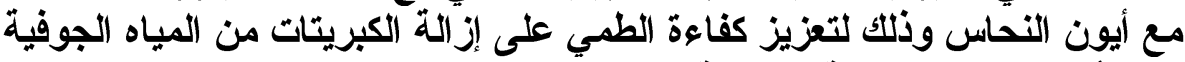

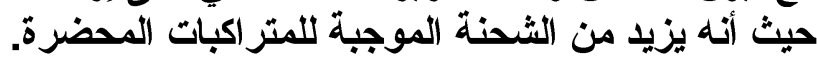

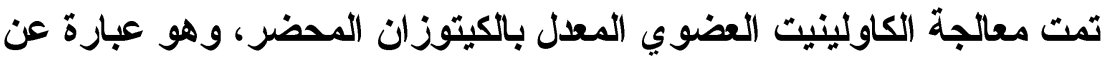

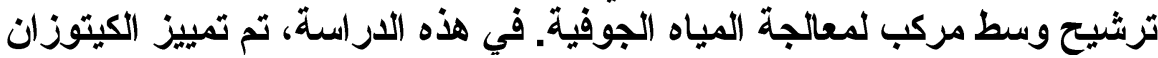

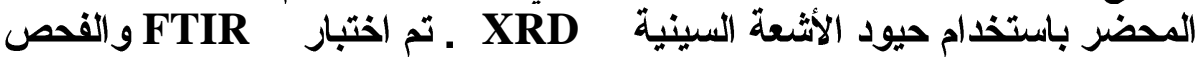

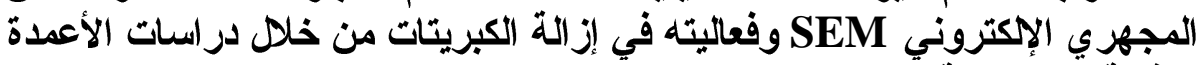

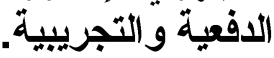



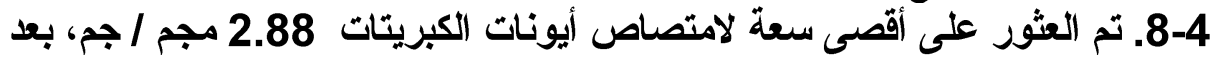

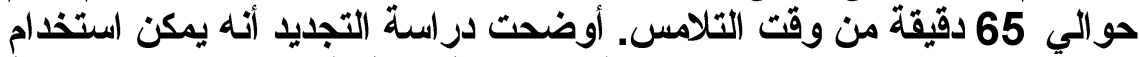

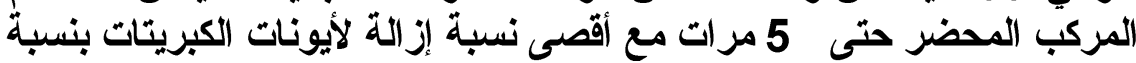

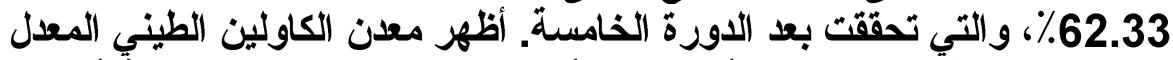
من الثيتوزان قُرة امتصاص أعلى تجاه أيونات الكبريتات مع مواد ماصةُ أخرى. 